\title{
A spectroscopic proton-exchange membrane fuel cell test setup allowing fluorescence x-ray absorption spectroscopy measurements during state-of-the-art cell tests
}

\author{
Olga Petrova, ${ }^{1}$ Christian Kulp, ${ }^{2, a)}$ Maurits W. E. van den Berg, ${ }^{1, b)}$ \\ Konstantin V. Klementiev, ${ }^{3}$ Bruno Otto, ${ }^{1}$ Horst Otto, ${ }^{1}$ Marco Lopez, ${ }^{4}$ \\ Michael Bron, ${ }^{2}$ and Wolfgang Grünert ${ }^{1, c}$ \\ ${ }^{1}$ Laboratory of Industrial Chemistry, Ruhr University Bochum, Bochum, Germany \\ ${ }^{2}$ Analytical Chemistry-Electroanalytics \& Sensors, Ruhr University, Bochum, Germany \\ ${ }^{3}$ Cells-Alba Synchrotron, Barcelona, Spain \\ ${ }^{4}$ Umicore Fuel Cells, Umicore \& Co KG, Hanau, Germany
}

(Received 16 December 2010; accepted 15 March 2011; published online 8 April 2011)

\begin{abstract}
A test setup for membrane-electrode-assemblies (MEAs) of proton exchange membrane fuel cells which allows in situ fluorescence $\mathrm{x}$-ray absorption spectroscopy studies of one electrode with safe exclusion of contributions from the counter electrode is described. Interference by the counter electrode is excluded by a geometry including a small angle of incidence $\left(<6^{\circ}\right)$ between primary beam and electrode layer. The cell has been constructed by introducing just minor modifications to an electrochemical state-of-the-art MEA test setup, which ensures realistic electrochemical test conditions. This is at the expense of significant intensity losses in the path of the incident beam, which calls for the brilliance of third-generation synchrotrons to provide meaningful data. In measurements on $\mathrm{Pt} / \mathrm{C}$ and $\mathrm{Pt}-\mathrm{Co} / \mathrm{C}$ cathodes combined with $\mathrm{Pt}-\mathrm{C}$ anodes $\left(\mathrm{H}_{2} / \mathrm{O}_{2}\right.$ feed $)$, good data quality was demonstrated both for the majority element $\mathrm{Pt}$ as well as for Co despite of a low areal Co density in the order of $0.02 \mathrm{mg} / \mathrm{cm}^{2}$. ( 2011 American Institute of Physics. [doi:10.1063/1.3574225]
\end{abstract}

\section{INTRODUCTION}

In recent years, the study of electrocatalysts for protonexchange membrane (PEM) fuel cells has been strongly promoted by the use of x-ray absorption spectroscopy (XAS). ${ }^{1}$ This technique gives access to information on the oxidation states of elements involved, on their mixing state (alloying/segregation), on the average particle size, on the electronic state of metals (d-band occupancy ${ }^{2}$ ), and on species adsorbed on the surface [ $\Delta \mu$-XANES (x-ray absorption near-edge structure) technique $\left.{ }^{3}\right]$. Such wealth of opportunities has triggered considerable effort to measure XAS data under conditions as close as possible to realistic reaction regimes.

This goal was first approached with electrochemical cells, in which the working electrode was combined with a conventional counter electrode (grafoil platelet, ${ }^{4}$ perforated gold foil,${ }^{5} \mathrm{Pt}$ gauze ${ }^{6}$ ) via a separator (Nafion membrane, ${ }^{4}$ electrolyte-soaked porous paper $^{5,6}$ ). XAS studies with real PEM fuel cells have to cope with the problem that stateof-the-art membrane-electrode-assemblies (MEA; anode and cathode deposited onto a PEM) contain significant amounts of platinum both in the cathode and in the anode. Therefore, in earlier cells for transmission XAS the catalyst in the beam path was removed from the counter electrode ${ }^{7}$ or non-Pt counter electrodes were used, ${ }^{8-11}$ which causes serious interference with the reaction regime. Fluorescence detection, which is mandatory for minority components, has also been

\footnotetext{
a) Present address: Institute of Chemistry, Martin Luther University HalleWittenberg, Halle (Saale), Germany.

b) Present address: crenox GmbH, Krefeld, Germany.

c) Author to whom correspondence should be addressed. Tel. +49 234322 2088. Fax +49 234321 4115. Electronic mail: w.gruenert@techem.rub.de.
}

extended to the measurement of Pt spectra. ${ }^{12}$ However, due to the very small thickness of catalyst layers and membrane, one has to expect significant contributions from the counter electrode platinum at the typical angles of primary beam incidence (around $45^{\circ}$ ). Therefore, Pd counter electrodes have been applied in fluorescence cells as well. ${ }^{9}$

We are presenting here a new cell construction in which the incoming $\mathrm{x}$-ray hits the electrode at a very small angle, which permits to exclude contributions from the counter electrode effectively. While this advantage is at the expense of considerable intensity losses, calling for light from a thirdgeneration synchrotron source, the measurement geometry can be easily incorporated into existing test equipment. This allows the simultaneous measurement of electrochemical and spectroscopic data under completely realistic conditions.

\section{EXPERIMENT}

\section{A. Cell design}

The cell is schematically depicted in Fig. 1 (a: exploded view, MEA and heating pad omitted, b: cross section along beam path). The thickness of the MEA $(\phi)$, and also the outlet aperture for the fluorescence radiation are exaggerated to demonstrate the principle. The construction is pressed together by screws (omitted) in the end plates $(\alpha)$, which are separated from the interior potentials by isolating layers $(\beta)$ and are fitted with heating pads $(\gamma)$. The collector plates $(\chi)$ drain the current generated at the electrodes $\left(\phi_{1}\right)$, which passes the gas diffusion layers (GDL), $\varepsilon$, and the bipolar plates ( $\delta$, wall thinned along beam path, $\left.\delta_{1}\right)$. The latter component directs the gases to the electrodes (gas inlets omitted) 


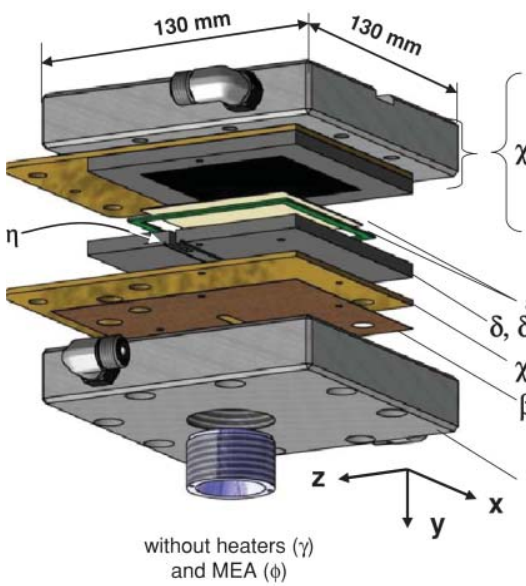

(a)

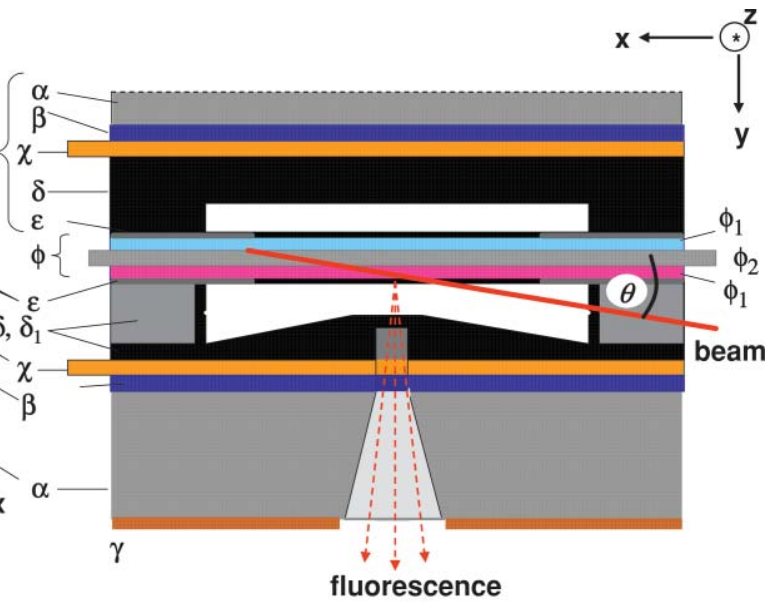

(b)

FIG. 1. (Color) Schematic views of the spectroscopic test cell. (a) Exploded view, MEA and heaters omitted, (b) cross section along beam path (x direction), looked upon from above, not to scale. $\alpha$ : end plates (thickness: $24 \mathrm{~mm}$ ), $\beta$ : isolating layers (thickness: $\approx 0.5 \mathrm{~mm}$ ), $\chi$ : collector plates (thickness: $2 \mathrm{~mm}$ ), $\delta$ : bipolar plates (thickness: $5 \mathrm{~mm}$ ) with flow fields, $\delta_{1}$ : wall material removed in beam path, $\varepsilon$ : gaskets and gas diffusion layers (interior part) (thickness: $60-90$ $\mu \mathrm{m}), \phi$ : MEA (thickness: $\approx 50-80 \mu \mathrm{m}), \phi_{1}$ : electrodes, $\phi_{2}$ : membrane, $\gamma$ : heaters, $\eta$ : adjustment slits.

via a number of parallel channels of the so-called flow field. One of these channels is recessed to allow beam passage to the spot of analysis. In Fig. 1(b), it can be seen that the beam enters this channel through a thinned section of the carbon wall and travels through the GDL before it hits the electrode. The fluorescence photons leave the flow field through another thinned wall section, proceeding to the detector through holes in the collector, the isolation, and the end plate. The temperature is measured in both end plates and in one of the bipolar plates (not shown).

For two reasons, the geometry of the setup excludes intensity from the counter electrode very reliably. First, the points where the beam hits the two electrodes is displaced along the beam direction x. In Fig. 1(b), this displacement is very pronounced, however, in reality, it is much smaller due to the minor MEA dimensions (membrane: $20 \mu \mathrm{m}$, electrodes: 10-20 $\mu \mathrm{m})$. With outlet apertures of several $\mathrm{mm}$ required to achieve acceptable intensity, this displacement alone may be insufficient to suppress undesired intensity from the counter electrode. However, at small angles, the beam path in the electrode studied increases strongly, with concomitant attenuation of the primary beam. This effect was tested experimentally as depicted in the inset of Fig. 2. In this run, the angle $\theta$ between MEA and primary beam was varied with the MEA completely exposed, i.e., parts $\alpha \ldots \delta$ in Fig. 1 removed on one side. While the beam impinged directly on the $\mathrm{Pt}-\mathrm{Ru} / \mathrm{C}$ anode of this MEA, intensity coming from the $\mathrm{Pt}-\mathrm{Co} / \mathrm{C}$ cathode on the rear side was monitored at the $\mathrm{CoK}$ edge (Fig. 2). It can be

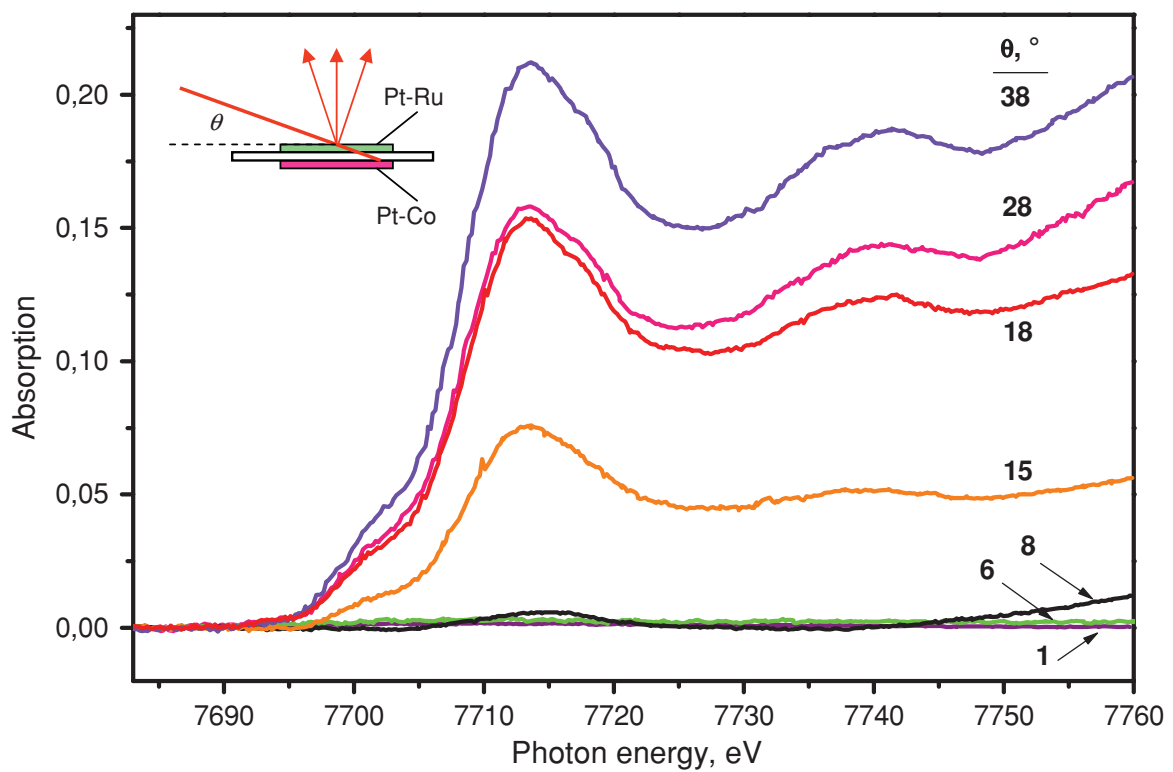

FIG. 2. (Color online) Investigation of main signal contamination by intensity from the counter electrode: Co XANES from a Pt-Co(1 : 1$) / C$ electrode located on the rear side of the MEA (front side: Pt-Ru/C), measured at different incident angles $\theta$ between beam and MEA. To allow variation of $\theta$, the MEA was exposed by removing parts $\alpha$ through $\delta$ on the front side (cf. Fig. 1). 
seen that significant Co intensity appeared only at an angle $\theta$ $>10^{\circ}$. As CoK radiation $(\approx 7710 \mathrm{eV})$ is somewhat softer than the $\mathrm{Pt} L$ edges $\left(\mathrm{Pt} L_{\mathrm{III}}: \approx 11560 \mathrm{eV}\right.$ ), the impact of the counter electrode will be slightly larger in the $\mathrm{Pt} L_{\text {III }}$ region. However, the combination of attenuation by absorption and by geometrical displacement makes sure that the counter electrode influence will be negligible in the $\theta$ range accessible in our cell (up to $\approx 6^{\circ}$ ).

The modifications introduced into the standard test cell design to allow acquiring XAFS data do not interfere with electrochemical measurements. One deviation from normal conditions concerns the linear gas velocity in the flow field channel used for beam passage, which is somewhat smaller in the deeper parts. However, just at the spot under investigation, the channel depth is identical with the standard depth, and so is the gas velocity. Another point of concern might be the temperature distribution. The plate heater $\gamma$ attached to the end plate at the measurement site spares the area of the fluorescence radiation cone (Fig. 1). However, the end plate provides a large heat capacity and the cone is sealed with Kapton foil to avoid inflow of cold air, thus, the temperature deviation at the spot of analysis below the $6 \mathrm{~mm}$ fluorescence exit aperture should be negligible at a typical cell temperature of $353 \mathrm{~K}$. The decreased wall thickness at some points of the bipolar plate $(\delta)$ did not cause problems neither with mechanical stability nor with sealing at 3 bar gas pressure. An initial version with a wider beam entrance field designed to allow analysis in three adjacent flow field channels had to be abandoned due to leakage problems, but with the present version with only one channel for analysis, leakage rates are below a level that could cause safety concerns.

Exact positioning of the cell relative to the primary beam is a prerequisite for any measurement with this setup. The beam has to be exactly parallel to the channel walls, and the surface of the electrode $\left(\phi_{1}\right)$ adjacent to the gas-diffusion layer $(\varepsilon)$ has to be found before the cell can be rotated to vary the angle of incidence. Two features have been included to support this adjustment: first, there are two grooves $(\eta)$ in the rear side of the modified bipolar plate [Fig. 1(a)], which allow alignment of the cell along the beam and serve as a starting point for the search of the analysis channel. Second, the walls of the bipolar plate have been cut thin at both sides although the fluorescence mode does not require such beam exit. The exit created allows fine-tuning the beam position in the analysis channel (for further adjustment details, see below).

\section{B. Experimental setup}

Figure 3 shows the gas supply and disposal scheme into which the fuel cell is integrated. Hydrogen (purity 6.0) and oxygen (purity 4.5) are fed to the cell, $\mathrm{N}_{2}$ (purity 4.6) is used for flushing purposes. The gases are moistened in the bubbler unit. From there, they flow to the cell in heated tubes. After passing through the cell, the gases are cooled and dried before disposing them in the exhaust lines. A back pressure regulator allows adjusting the gas pressure in the system in the range of $1 \ldots 5$ bar. The whole setup is operated via a Labview control scheme. The cell voltage is measured by two pins pressed directly to the bipolar plates (not shown). Temperature control is based on the thermocouple in a bipolar plate, for cooling, a fan is installed (not shown).

For independent variation of cell parameters, an electronic load (EL500, Zentro-Elektrik, Pforzheim) is employed, to which the cell is connected in series with a power supply (XFR 7.5-140, Xantrex, Vancouver). A support voltage of $4.0 \mathrm{~V}$ applied during the experiments ensures the operability of the electronic load even at low voltage outputs of the fuel cell.

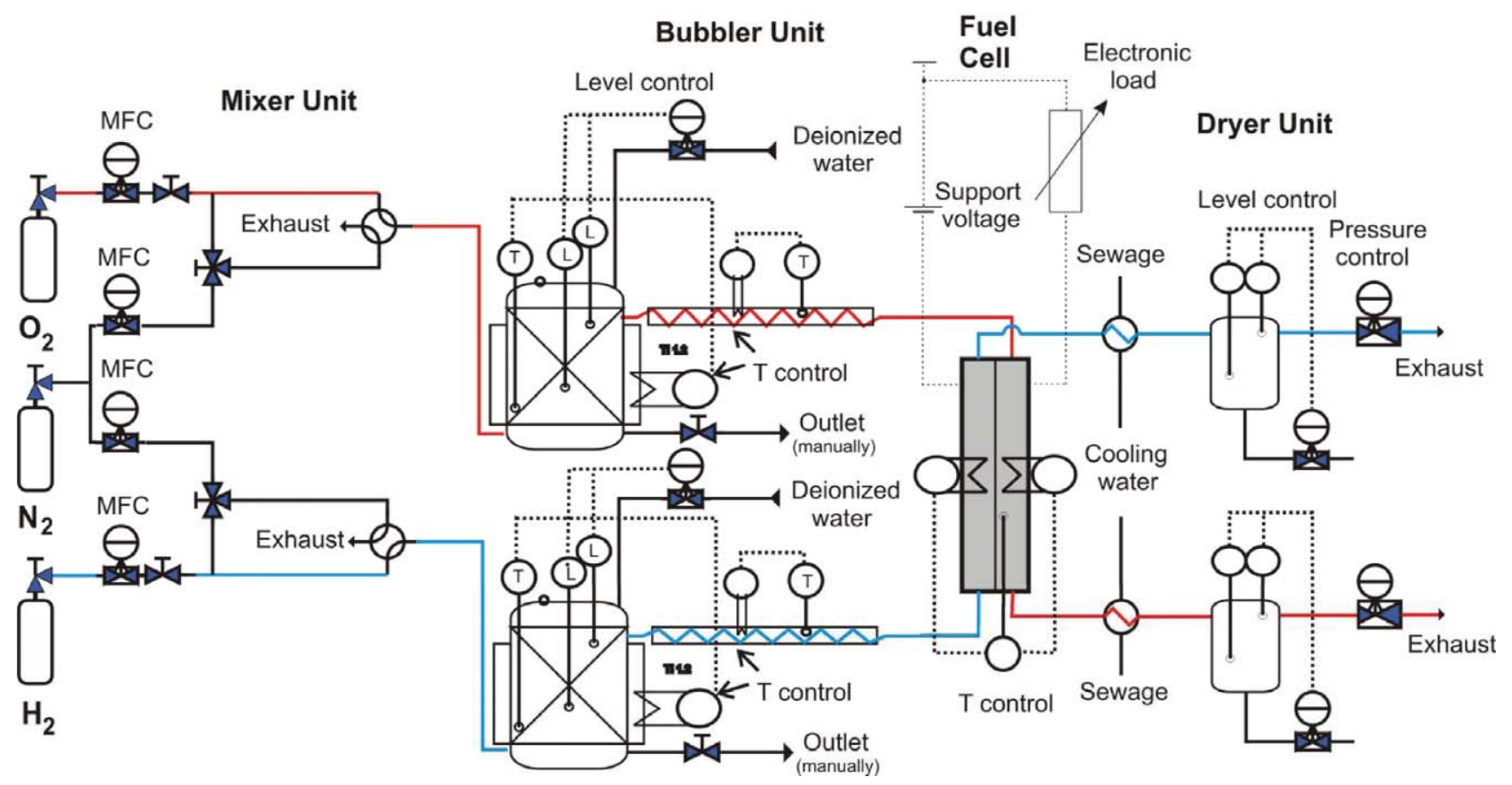

FIG. 3. (Color online) Integration of spectroscopic fuel cell in test setup containing gas supply, moistening, disposal, and electric test facilities. 


\section{Typical experiment}

Besides the general installation of the setup depicted in Fig. 3, a major step in the utilization of the cell is its correct alignment to the x-ray beam, which is done with a goniometer table. Usually this provides satisfactory parallelism between beam and the cell horizontal ( $\mathrm{x}$ in Fig. 1). Coarse positioning is made using fluorescence paper, tracing the beam position via cameras. After one of the adjustment grooves $\eta$ [Fig. 1(a)] has been found, the exact position of the beam is determined by a horizontal scan (z direction). From the center of the smaller groove, the beam is moved into the cutout of the bipolar plate via predetermined steps. There the exact position is again determined by repeated $\mathrm{y}$ and $\mathrm{z}$ scans recording the transmitted radiation behind the cell. The beam is then moved to touch the electrode surface, ideally at zero angle of incidence $\theta$, and the cell is rotated to scan the angle $\theta$ recording the fluorescence intensity out of the end plate. As it is usually impossible to place the center of rotation exactly into the plane of the electrode, this rotation will cause the beam spot to move along the $\mathrm{x}$ direction, but the spot can be brought back by scanning the y direction. An optimized alignment is then achieved by repeated scans of $\theta$ and $y$.

After this, the reaction gases are admitted to the cell by switching the 4-way valves in the mixer unit (Fig. 3), and measurement parameters are established. The cell has been used without problems at $353 \mathrm{~K}$ and 3 bar gas pressure, but the data reported here refer to 1.5 bar. The gases are saturated with steam in the bubblers where their humidification (typically $70 \%$ ) is controlled by the bubbler temperature. With $25 \mathrm{~cm}^{2}$ electrodes, gas flows of up to $50 \mathrm{l} / \mathrm{h}$ of $\mathrm{H}_{2}$ and $\mathrm{O}_{2}$ were used. While this is far beyond the stoichiometric needs, it was required to avoid droplet formation in the GDL (vide infra). In work with fresh MEAs, an $8 \mathrm{~h}$ stabilization period at $12.5 \mathrm{~A}$ $\left(0.5 \mathrm{~A} / \mathrm{cm}^{2}\right)$ preceded other experiments. It was accompanied by a significant increase of the cell voltage. A typical experiment with a MEA would include the recording of a currentvoltage curve between open circuit and $1 \mathrm{~A} / \mathrm{cm}^{2}$, with XAS measurements at different steady states in the curve. Alternatively, the MEA may be subjected to stress tests or variation of conditions, e.g., degree of moisture.

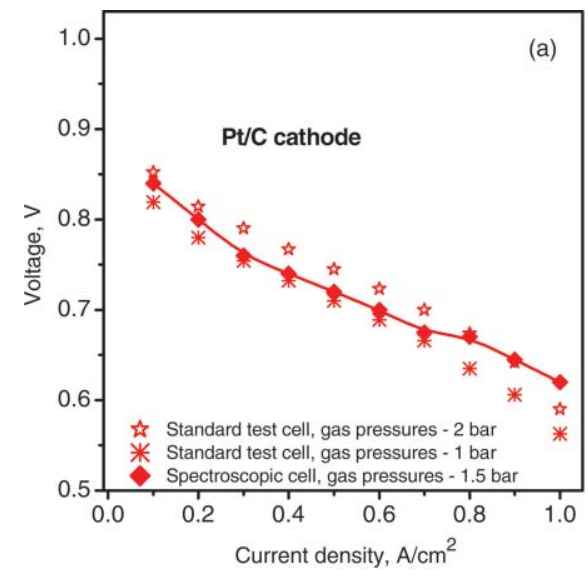

Due to intensity losses caused by the carbon walls and by beam passage through the porous gas diffusion layer [ $\varepsilon$ in Fig. 1(a)] at a small angle, the new cell requires the brilliance of a third-generation synchrotron to provide reliable data. Even there, data acquisition time was $>30$ min for a full EXAFS spectrum of a minority element (Co, vide infra). Experiments at a second-generation synchrotron were, however, highly valuable for feasibility studies and elaboration of adjustment strategies. Due to the primary beam traveling through the gas diffusion layer, water condensation which may happen at large current densities has to be strictly avoided in this setup. The water will form droplets just in the pores of the layer which cause strong erratic noise on the fluorescence signal. As mentioned above, this was avoided by large gas flow rates or additionally by lowering the gas humidity.

\section{EXPERIMENTAL RESULTS: EXAFS ANALYSIS OF CATHODES IN WORKING MEAS}

Typical results obtained with the setup are shown in Figs. 4-7. In Fig. 4, polarization curves measured during acquisition of XAS data are shown [Fig. 4(b)] and compared with data measured in a different setup using an unmodified cell [Fig. 4(a)]. The data were taken with a monometallic cathode containing $0.4 \mathrm{mg} \mathrm{Pt} / \mathrm{cm}^{2}$ (anode: $0.2 \mathrm{mg} / \mathrm{cm}^{2} \mathrm{Pt} / \mathrm{C}$ ). As the reference measurements were not available at 1.5 bar, our operando data are bracketed by data for 1 and 2 bar, which were measured in industrial reference equipment. At most of the points, the operando data are well between the reference data though somewhat nearer to the 1 bar series at higher loads. The significantly better behavior of the operando data at $\geq 0.8 \mathrm{~A} / \mathrm{cm}^{2}$ may have been caused by significantly increased gas flows which were established to get rid of water droplets that had been formed in the GDL (see above). In Fig. 4(b), a polarization curve of a MEA with $\mathrm{PtCo} / \mathrm{C}$ cathode $\left(0.18 \mathrm{mg} \mathrm{Pt} / \mathrm{cm}^{2}\right.$, anode: $\left.0.2 \mathrm{mg} / \mathrm{cm}^{2} \mathrm{Pt} / \mathrm{C}\right)$ is also shown. It is slightly below that measured with the Pt cathode. Given the more than double Pt loading of the latter, the data suggest that the mass activity of the PtCo cathode was considerably larger than that of the Pt cathode.

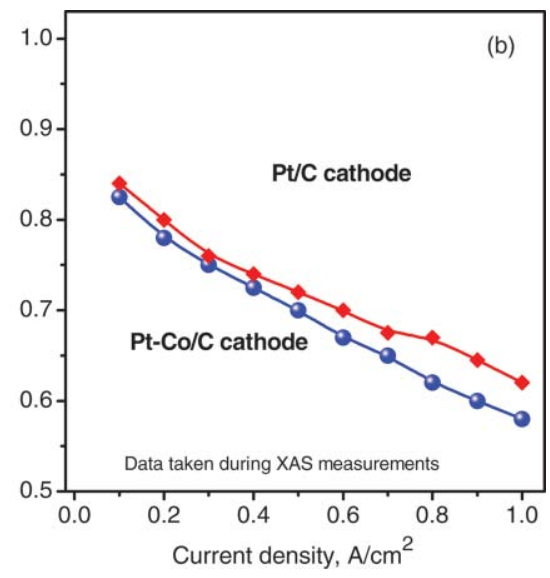

FIG. 4. (Color online) Current-voltage curves measured with different MEAs. $\mathrm{p}_{\mathrm{O}_{2}}=\mathrm{p}_{\mathrm{H}_{2}}=1.5$ bar if not state otherwise, for more details on measurement conditions and electrode properties, see text. (a) Cathode: $\mathrm{Pt} / \mathrm{C}\left(0.4 \mathrm{mg} \mathrm{Pt} / \mathrm{cm}^{2}\right)$, comparison with data from a standard setup, obtained at different gas pressure, (b) $\mathrm{Pt}-\mathrm{Co} / \mathrm{C}$ cathode $\left(0.18 \mathrm{mg} \mathrm{Pt} / \mathrm{cm}^{2}\right)$. 

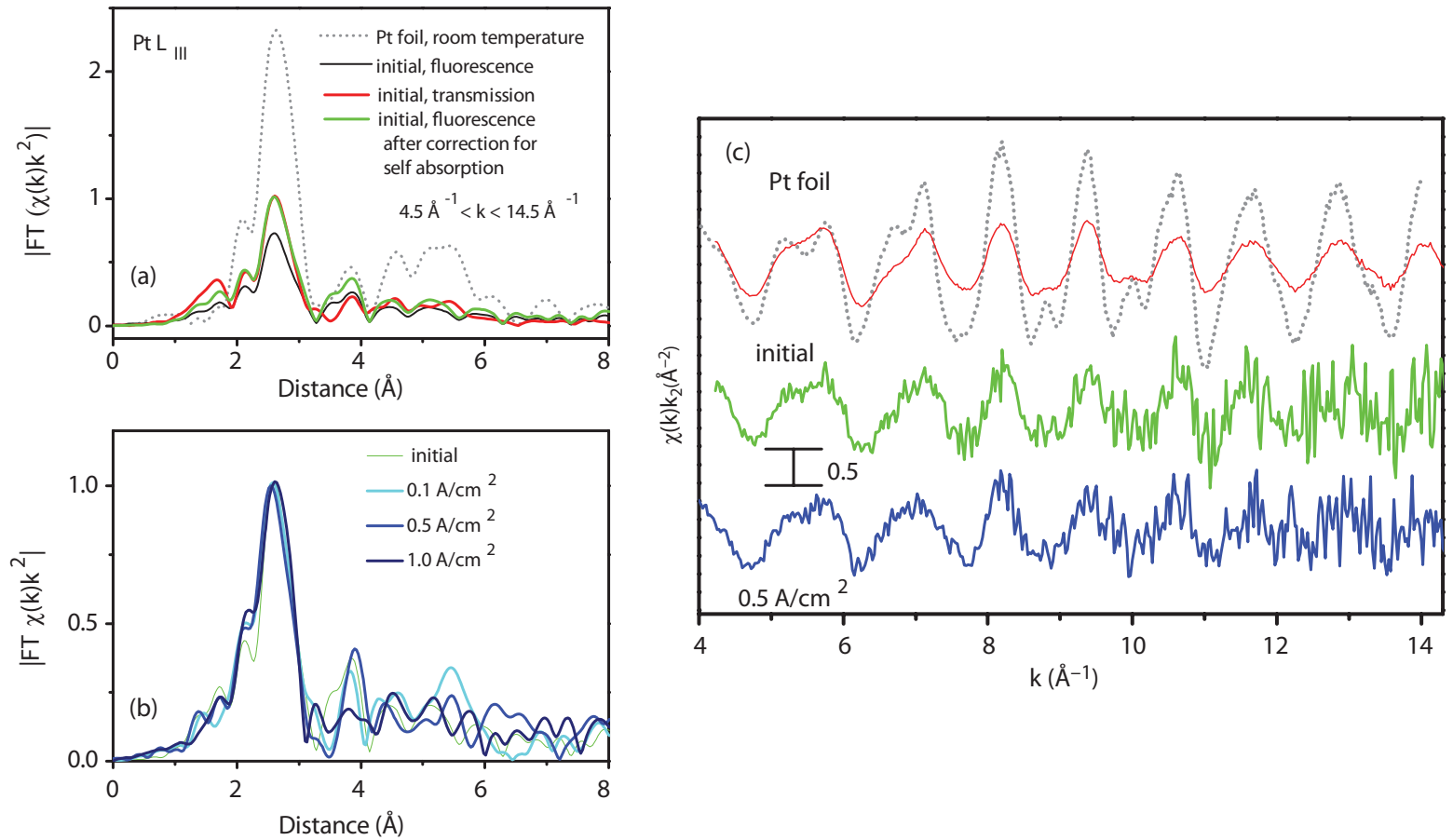

FIG. 5. (Color) Pt $L_{\mathrm{III}}$ EXAFS spectra measured with a Pt/C cathode at different current densities, compared with Pt foil. (a) $\mathrm{k}^{2}$-weighted, Fourier-transformed spectra of initial Pt/C cathode measured in transmission (red, half-MEA) and out of the cell (black), all under air and at room temperature; green curve: fluorescence spectrum after self-absorption correction, (b) $\mathrm{k}^{2}$-weighted, Fourier-transformed spectra of cathode measured under different current densities at $353 \mathrm{~K}$, (c) comparison of original $\mathrm{k}^{2}$-weighted transmission spectra of Pt foil and of initial Pt/C cathode (half-MEA) with fluorescence spectra from Pt/C cathode (corrected for self-absorption) in initial state and during operation at $0.5 \mathrm{~A} / \mathrm{cm}^{2}$.

Examples of the fluorescence-XAFS data measured during operation of the MEA with the $\mathrm{Pt} / \mathrm{C}$ cathode are given in Fig. 5. For comparison, room-temperature transmission spectra of a Pt foil and of the initial catalyst (half-MEA) are included in Figs. 5(a) and 5(c). The comparison of the two initial spectra [Fig. 5(a), black and red curves] suggests that fluorescence data from this very concentrated sample have to be corrected for self-absorption effects. This was done within the software package "Viper for Windows" 13 following the algorithm of Iida and Noma, ${ }^{14}$ and the results are shown in Figs. 5(a) and 5(c) as green curves. Slight differences

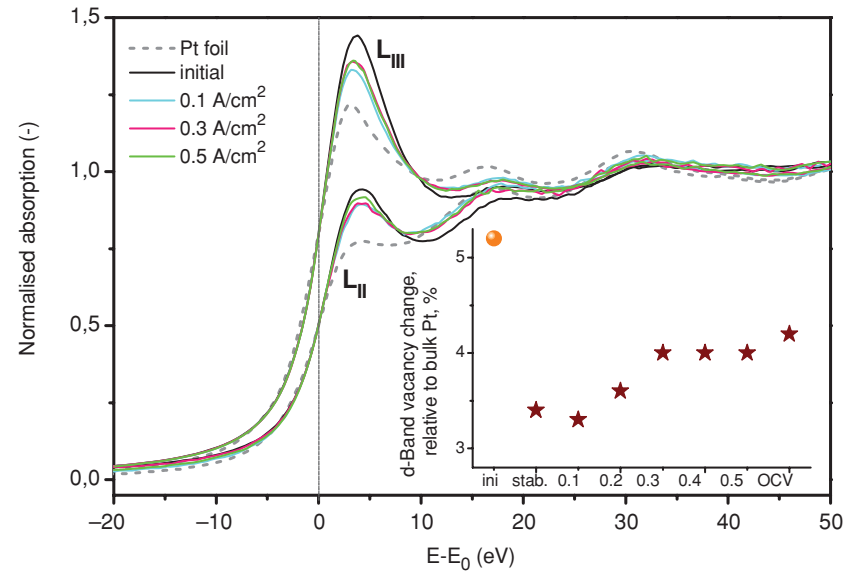

FIG. 6. (Color online) Pt $L_{\mathrm{III}}$ and $L_{\mathrm{II}} \mathrm{XANES}$ of Pt foil and of a Pt/C cathode at different current densities (fluorescence measurements, corrected for selfabsorption). Inset: Assessment of d-band occupancy: percentage decrease relative to bulk Pt. remained in particular below $2 \AA$ (uncorrected), which may be near the limits of experimental error.

Although the temperature of the operando measurement was somewhat above room temperature it is obvious from the low intensity of all scattering paths that the Pt particles in the cathode are small. In addition, the peak asymmetry suggests the presence of a light neighbor $(\mathrm{O}$ or $\mathrm{C})$. This was confirmed by a preliminary fit of the spectrum at $0.5 \mathrm{~A} / \mathrm{cm}^{2}$ on FEFF-8.10 theoretical standards, ${ }^{15}$ which resulted in a Pt-Pt first coordination number of 9.7 at a distance of $0.274 \mathrm{~nm}$ (Pt foil: $0.277 \mathrm{~nm}$ ), with an additional shell (O assumed) at $0.201 \mathrm{~nm}$. Figure 5(b) shows that there was no significant change in the EXAFS spectra along the current-voltage curve (cf. Fig. 4). In Fig. 5(c), representative k-space spectra are shown in order to give an impression on data quality [station: BM29 at ESRF, Grenoble (France)]. Although the impact of experimental noise was significant, oscillations could be well discerned up to $\mathrm{k}=14 \AA^{-1}$.

Better data quality is, of course, available in the XANES region, which is of particular interest for in situ studies as it gives access to the electronic state of metals (d-band occupancy $^{2}$ ), and to the characterization of adsorbed species $\left(\Delta \mu\right.$-XANES technique $\left.{ }^{3}\right)$. The Pt d-band occupancy may be derived from the difference between $\mathrm{L}_{3}$ and $\mathrm{L}_{2}$ edge XANES, which are plotted relative to the corresponding edges for different states in Fig. 6. The d-band vacancies were assessed as outlined in Refs. 2 and 16, and the results are given in the inset, where the percentage change relatively to the d-band vacancies in bulk Pt is shown. A significant drop can be seen between the initial state (in air) and the state after stabilization, probably because of the removal of some 

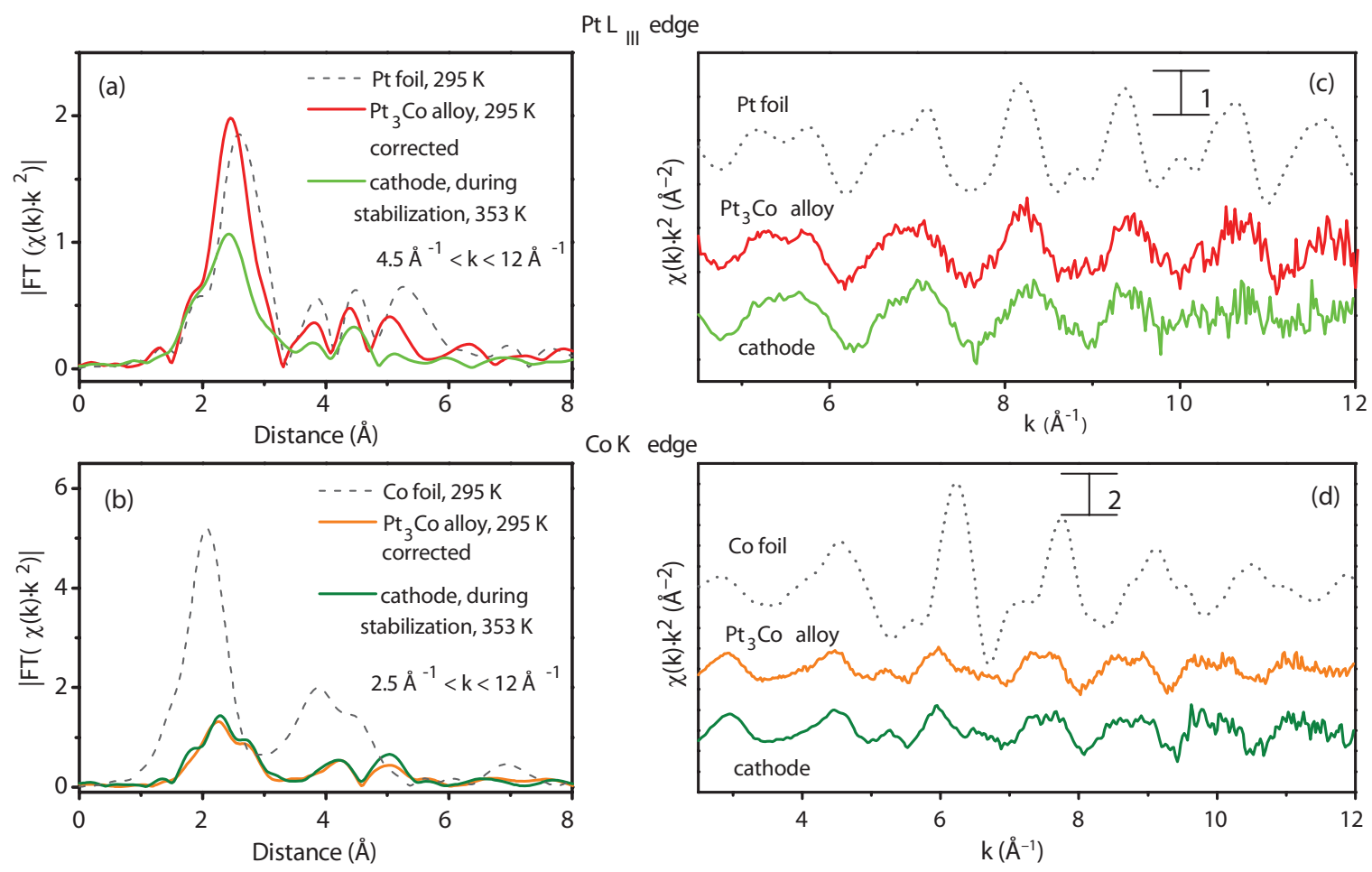

FIG. 7. (Color) EXAFS spectra measured with a Pt-Co/C cathode during stabilization period $\left(353 \mathrm{~K}, 0.5 \mathrm{~A} / \mathrm{cm}^{2}\right)$, compared with standards. (a, b) $\mathrm{k}^{2}$-weighted, Fourier-transformed spectra at $\mathrm{Pt} L_{\mathrm{III}}$ edge (a) and $\mathrm{Co} K$ edge (b), (c, d) comparison of original $\mathrm{k}^{2}$-weighted spectra at $\mathrm{Pt} L_{\mathrm{III}}$ edge (c) and $\mathrm{Co} K$ edge (d). The bulk $\mathrm{PtCo}_{3}$ reference alloy was measured in fluorescence mode at room temperature, the spectra were corrected for self-absorption effects.

oxidized species. With increasing current density, the difference to bulk Pt increases again. The effect is rather small, between $3.3 \%$ and $4.2 \%$, causing the number of unfilled $d$ states (Pt: 1.60) to increase just from 1.65 to 1.67 . However, the absence of significant scatter in the series shows that the method can differentiate these minute changes. In a subsequent measurement at open circuit, the d-band vacancies remained at the previous level (Fig. 6, inset) which suggests that the changes are not related to the changes in electrode potential. Rather, we track here irreversible changes in the structure of the metal particles which are probably too small to be reflected in the geometrical quantities accessible via EXAFS [cf. Fig. 5(a)].

In the study with the $\mathrm{Pt}-\mathrm{Co} / \mathrm{C}$ cathode, meaningful EXAFS spectra could be acquired also for the minority element Co thanks to the brilliance of a horizontally focusing beamline (SuperXAS at SLS, Villigen, Switzerland). By comparing the Co XANES of the initial sample measured in transmission and in fluorescence (i.e., using the cell described here), it was made sure that self-absorption correction was not required for this electrode. The Fourier-transformed spectra are shown in Figs. 7(a) and 7(b). They show that both Co and Pt seem to be almost completely bound in $\mathrm{Pt}_{3} \mathrm{Co}$ alloy particles in the cathode, which means that the Co loading was only $\approx 0.02 \mathrm{mg} / \mathrm{cm}^{2}(\approx 10 \mathrm{wt}$. $\%$ of metal loading). The data quality is exemplified in Figs. 7(c) and 7(d) where the Pt $L_{\text {III }}$ and $\mathrm{Co} K$ spectra from an operando measurement taken during the stabilization period $\left(\mathrm{I}=0.5 \mathrm{~A} / \mathrm{cm}^{2}\right)$ are shown. They compare well with fluorescence data of a bulk $\mathrm{Pt}_{3} \mathrm{Co}$ alloy made at a second-generation synchrotron. Therefore, even with the low Co areal density of $\approx 0.02 \mathrm{mg} / \mathrm{cm}^{2}$, acceptable spectra could be obtained. The similarity of the spectra of the bulk al- loy standard and cathode catalyst and the lack of amplitude decay at longer distances in particular in the Co spectrum [Fig. 7(b)] suggest that the size of the alloy particles is significantly larger than that of the Pt particles in the previous example [Fig. 4(a)].

Further results on this type of cathode and its structural changes during operation of the cell will be published elsewhere.

\section{CONCLUSIONS}

A state-of-the art single-MEA fuel cell test setup has been modified to allow operando fluorescence XAS studies with safe exclusion of interference by the counter electrode. This has been achieved by a geometry including a small angle of incidence $\left(<6^{\circ}\right)$ between primary beam and electrode surface. While the setup requires the brilliance of thirdgeneration synchrotrons for reasonable utilization due to inevitable intensity losses in the primary beam path, the minor modifications relative to the standard cell construction ensure realistic electrochemical test conditions. In measurements in $\mathrm{H}_{2} / \mathrm{O}_{2}$ feed, $\mathrm{Pt} / \mathrm{C}$ and $\mathrm{Pt}-\mathrm{Co} / \mathrm{C}$ cathodes combined in MEAs with $\mathrm{Pt}-\mathrm{C}$ anodes were studied and good data quality was demonstrated both for the majority element $\mathrm{Pt}$ as well as for Co despite of a low Co loading in the order of $0.02 \mathrm{mg} / \mathrm{cm}^{2}$.

\section{ACKNOWLEDGMENTS}

The work was funded by the German Science Foundation (Grant Nos. Gr 1447/16-1 and Br 2244/5-1), which is gratefully acknowledged. We thank Ms. C. Standfest and 
Mr. Gerhard Heinz (Solvicore $\mathrm{GmbH}$ ) for their invaluable advice in practical problems, and beamline scientists Dr. Adam Webb, Dr. Edmund Welter, and Dr. Roman Chernikov [Hasylab Hamburg (Germany), stations X and C], Dr. Pieter Glatzel and Dr. Carmelo Prestipino [ESRF Grenoble (France), stations ID 26 and BM29], Dr. Messaoud Harfouche and Dr. Maarten Nachtegaal [SLS Villigen (Switzerland), station SuperXAS] for their active support during synchrotron work.

${ }^{1}$ A. E. Russell and A. Rose, Chem. Rev. 104, 4613 (2004).

${ }^{2}$ A. N. Mansour, J. W. Cook, Jr., and D. E. Sayers, J. Phys. Chem. 89, 462 (1984).

${ }^{3}$ C. Roth, B. N. Benker, T. Buhrmester, M. Mazurek, M. Loster, H. Fuess, D. C. Koningsberger, and D. E. Ramaker, J. Am. Chem. Soc. 127, 14607 (2005).

${ }^{4}$ J. McBreen and S. Mukerjee, J. Electrochem. Soc. 142, 3399 (1995).

${ }^{5}$ M. E. Herron, S. E. Doyle, S. Pizzini, K. L. Roberts, J. Robinson, G. Hards, and F. C. Walsh, J. Electroanal. Chem. 324, 243 (1992).

${ }^{6}$ S. Maniguet, R. J. Mathew, and A. E. Russell, J. Phys. Chem. B 104, 1998 (2000).
${ }^{7}$ C. Roth, N. Martz, T. Buhrmester, J. Scherer, and H. Fuess, Phys. Chem. Chem. Phys. 4, 3555 (2002).

${ }^{8}$ R. Viswanathan, G. Y. Hou, R. X. Liu, S. Bare, F. Modica, G. Mickelson, C. U. Segre, N. Leyarovska, and E. S. Smotkin, J. Phys. Chem. B 106, 3458 (2002).

${ }^{9}$ E. Principi, A. Di Cicco, A. Witkowska, and R. Marassi, J. Synchrotron Radiat. 14, 276 (2007); E. Principi, A. Witkowska, S. Dsoke, R. Marassi, and A. Di Cicco, Phys. Chem. Chem. Phys. 11, 9987 (2009).

${ }^{10}$ M. Tada, S. Murata, T. Asakoka, K. Hiroshima, K. Okumura, H. Tanida, T. Uruga, H. Nakanishi, S. Matsumoto, Y. Inada, M. Nomura, and Y. Iwasawa, Angew. Chem. Int. Ed. 46, 4310 (2007).

${ }^{11}$ R. J. K. Wiltshire, C. R. King, A. Rose, P. B. Wells, M. P. Hogarth, D. Thompsett, and A. E. Russell, Electrochim. Acta 50, 5208 (2005).

${ }^{12}$ C. Roth, N. Benker, M. Mazurek, F. Scheiba, and H. Fuess, Adv. Eng. Mater. 7, 952 (2005).

${ }^{13}$ K. V. Klementiev, Viper for Windows, Ver. 10.1., freeware, http://www.cells.es/ Beam-lines/CLAESS/software/viper.html

${ }^{14}$ A. Iida and T. Noma, Jpn. J. Appl. Phys. 32, 2899 (1993).

${ }^{15}$ A. L. Ankudinov, B. Ravel, J. J. Rehr, and S. D. Conradson, Phys. Rev. B 58, 7565 (1998).

${ }^{16}$ F. Y. Lai, L. S. Sarma, H. L. Chou, D. G. Liu, C. A. Hsieh, J. F. Lee, and B. J. Hwang, J. Phys. Chem. C 113, 12674 (2009). 